\title{
Suppression of Immune Complex-Induced Inflammation by the Chemotactic Factor Inactivator
}

\author{
Kent J. Johnson, Thomas P. Anderson, and Peter A. Ward \\ From the Department of Pathology, University of Connecticut Health Center, Farmington, \\ Connecticut 06032
}

A B S T R A C T Small amounts $\left(10^{-10} \mathrm{~mol}\right)$ of purified human chemotactic factor inactivator (CFI) suppress leukocytic infiltration, permeability changes, and hemorrhage associated with acute immune complexinduced injury in rats. The reversed passive dermal Arthus reaction and acute immune complex-induced alveolitis in rats have served as the model systems of inflammation. The mechanism of inhibition does not appear to relate to interference with formation and deposition of immune complexes, or with fixation of complement in vitro or in vivo. Human CFI inhibits in vitro the chemotactic activity generated in complement-activated rat serum. The inhibitory effects of human CFI are not seen if it is first heat inactivated. The data provide the first direct support for the conclusion that CFI has anti-inflammatory activity.

\section{INTRODUCTION}

The inflammatory response can be suppressed by a variety of methods, each of which blocks one or more steps in a sequence leading to increased vasopermeability and the accumulation of leukocytes. Examples of anti-inflammatory agents include corticosteroids which, amont other things, suppress chemotactic responses of leukocytes (1), complement-blocking agents that inactivate substrates involved in the generation of inflammatory mediators (2), neutrophil-depleting agents (3), and nonsteroidal drugs (like aspirin) that block prostaglandin synthesis (4).

Present in normal human serum is a chemotactic factor inactivator (CFI) ${ }^{1}$ that irreversibly inhibits leukotactic factors, presumably by its aminopeptidase activity $(5,6)$. In humans with increased levels of CFI in the serum, an association has been found with defective expression of inflammatory reactions as mani-

Received for publication 15 October 1976 and in revised form 20 January 1977.

${ }^{1}$ Abbreviations used in this paper: BSA, bovine serum albumin; CFI, chemotactic factor inactivator. fested by skin tests $(7-10)$. These observations have suggested that CFI is an important regulator of the inflammatory response. In this communication direct evidence is presented to show that purified human CFI is able to block acute inflammatory reactions induced in rat dermis and lung by immune complexes.

\section{METHODS}

Immunologic vasculitis. Reversed passive Arthus reactions were induced in $250-\mathrm{g}$ male Sprague-Dawley rats by the intradermal injection of $100 \mu \mathrm{g}$ antibody nitrogen to bovine serum albumin (BSA). This antibody preparation was obtained by isolation of the IgG fraction from immune rabbit serum. Antibody titers were determined by quantitative precipitin reactions. BSA was injected intravenously in the amount of $10 \mathrm{mg}$ (in $0.5 \mathrm{ml}$ ). Details of the techniques are given elsewhere (2). In some experiments, the permeability changes were determined by the intravenous injection of $20 \mu \mathrm{g}$ homologous rat IgG isolated from normal rat serum and labeled with ${ }^{125} \mathrm{I}$ (11). A given sample of ${ }^{125} \mathrm{I}-$ IgG containing $10^{5} \mathrm{cpm}$ was injected intravenously together with the BSA into each animal. Appearance of the labeled IgG in skin sites served as a marker of permeability. The degree of permeability in 2-h Arthus reactions was expressed as the amount of radioactivity (determined by gamma ray emission in a crystal scintillation counter) in a 25 $\mathrm{mm}$ skin site. These procedures have been described in detail in a recent publication (11). Vascular damage in the 4-h reaction sites was determined by measurements of diameters of hemorrhage. All biopsy sites were quick-frozen for immunofluorescent assessment of reactant proteins (BSA and rat C3), while portions of all reaction sites were fixed in formaldehyde and processed for routine light microscopy (2).

Formalin-fixed tissue sections stained with hematoxylin and eosin were assessed by light microscopy for intensity of the infiltration by neutrophils. The following grading system was used: \pm , margination and early diapedesis of neutrophils: $1^{+}$, early perivascular infiltration; $2^{+}$, interstitial infiltration and pericapillary infiltration in muscularis layer; $3^{+}$, diffuse interstistial infiltration; $4^{+}$, heavy infiltrates in all cell layers of skin (subepithelial, dermal, subdermal, muscular, and subcutaneous zones). These criteria were established in earlier studies (2).

The grading of the inflammatory changes in the lung were: \pm , minimal presence of neutrophils in interstitial areas; $1^{+}$, presence of large numbers of neutrophils in the intersti- 
TABLE I

Suppression by Purified Human CFI of Chemotactic Activity in Activated Rat Serum

\begin{tabular}{lrr}
\hline \multicolumn{1}{c}{ Material tested } & $\begin{array}{c}\text { Chemotactic } \\
\text { activity }\end{array}$ & Inactivatio \\
\hline & counts/hpf & $\%$ \\
Experiment A & & \\
None & 30 & - \\
Activated serum & 320 & - \\
Activated serum + CFI $(10 \mu \mathrm{l})$ & 270 & 4 \\
Activated serum + CFI $(20 \mu \mathrm{l})$ & 210 & 25 \\
Activated serum + CFI $(50 \mu \mathrm{l})$ & 120 & 57 \\
Activated serum + heated CFI $(50 \mu \mathrm{l})$ & 310 & 0 \\
& & \\
Experiment B & 0 & - \\
None & 305 & - \\
Activated serum & 195 & 36 \\
Activated serum + CFI $(10 \mu \mathrm{l})$ & 111 & 64 \\
Activated serum + CFI $(20 \mu \mathrm{l})$ & 85 & 72 \\
Activated serum + CFI $(50 \mu \mathrm{l})$ & 105 & 66 \\
Activated serum + CFI $(100 \mu \mathrm{l})$ & & \\
\hline
\end{tabular}

* $1 \mathrm{ml}$ fresh rat serum was incubated with $10 \mathrm{mg}$ zymosan at $37^{\circ} \mathrm{C}$ for $1 / 2 \mathrm{~h}$, followed by centrifugal removal of zymosan. In all cases, $50 \mu$ l activated serum was used. When purified CFI was added, the mixture was incubated at $37^{\circ} \mathrm{C}$ for $1 / 2 \mathrm{~h}$ before dilution to $1.0 \mathrm{ml}$ and chemotactic assay.

tial areas of lung; $2^{+}$, interstitial localization of neutrophils and early appearance of neutrophils along alveolar walls; $3^{+}$, large numbers of neutrophils in an interstitial location and along alveolar walls with occlusion of nearly half the alveolar spaces with neutrophils; $4^{+}$, similar to findings in $3^{+}$, but with complete occlusion of alveolar spaces by neutrophils.

Acute immune complex-induced alveolitis. The specifics of this reaction are fully described elsewhere (11). The same reagents were used as employed for the reversed passive Arthus reactions. After intratracheal cannulation, $100 \mu \mathrm{g}$ $\mathrm{N}$ anti-BSA was instilled intrabronchially, after which BSA (10 mg) with small amounts (see above) of ${ }^{125}$ I-labeled rat IgG was injected intravenously. Reactions were allowed to progress over a $2-\mathrm{h}$ period, after which time $1.0 \mathrm{ml}$ blood was obtained and the amount of radioactivity determined. After lavage of the pulmonary circulation with $5 \mathrm{ml}$ saline injected into the right ventricle of the heart, lungs were obtained and assessed for radioactivity. One-half of each lobe of lung was fixed in formaldehyde and assessed by light microscopy for inflammatory changes in formalin-fixed tissue sections. A small part of each remaining lobe was frozen for assessment by immunofluorescence for the presence of antigen (BSA) and antigen (rabbit IgG) in the tissue sections. The remainder of lung was homogenized and the supernatant fluid assessed spectrophotometrically for the presence of hemoglobin, as a measure of the degree of hemorrhage. These procedures are fully described in a recent publication (11).

Chemotactic factor inactivator (CFI). This was purified from human serum by a sequence of chromatographic steps involving precipitation by salt, ion exchange, and gel filtration. By the use of hydrophobic resins, it has been possible to purify the CFI in a manner not previously obtained. Details regarding modifications of previously de- scribed procedures will be published elsewhere. ${ }^{2}$ The resulting CFI appeared in analytical (basic) acrylamide cells stained with Coomassie Blue as a single band in the alpha globulin region (12).

When used in vivo, $100 \mu \mathrm{l}$ CFI containing $12 \mu \mathrm{g}$ protein (except as otherwise indicated) was mixed with $100 \mu \mathrm{l}$ of the antibody preparation. The non-CFI-treated dermal sites and lungs received $100 \mu$ lantibody mixed with 100 $\mu l$ phosphate-buffered ( $\mathrm{pH} 7.4$ ) saline. In some experiments CFI was preheated at $56^{\circ} \mathrm{C}$ for $2 \mathrm{~h}$ before use, to destroy its activity. Various controls and replicate sites were prepared, as described in the appropriate tables.

Chemotaxis assay. In vitro leukotactic assays were performed with rabbit neutrophils obtained from glycogeninduced peritoneal exudates. Details of the assay are given elsewhere (5). Rat serum was chemotactically activated by incubation with zymosan, $10 \mathrm{mg} / \mathrm{ml}$ serum, at $37^{\circ} \mathrm{C}$ for $1 / 2$ $h$ (13). Zymosan particles were then removed by centrifugation and chemotactically activated serum tested by itself or after incubation with purified human CFI.

\section{RESULTS}

Suppression in vitro of leukotactic factors by CFI. Two experiments, described in Table I, were performed to determine the ability of purified human CFI to inhibit the chemotactic activity generated by incubation of rat serum with zymosan. The chemotactic activity was inhibited by CFI in a dose-dependent manner. In experiment $A$ it was also shown that CFI heated at $56^{\circ} \mathrm{C}$ for $2 \mathrm{~h}$ was, as expected, no longer able to inhibit the chemotactic activity in rat serum. These experiments indicate that human CFI can inhibit the chemotactic activity generated in rat serum by activation of complement. It has previously been shown that the chemotactic activity is associated with products of C5 (13).

Suppression of inflammation in dermal Arthus reaction. To assess the effect of CFI on the dermal Arthus reaction, it was first necessary to determine the degree of reproducibility of vasopermeability changes

\begin{tabular}{|c|c|c|c|c|c|}
\hline \multicolumn{6}{|c|}{$\begin{array}{c}\text { TABLE II } \\
\text { Reproducibility of Permeability Changes in Arthus Sites }\end{array}$} \\
\hline \multirow[b]{2}{*}{ Animal no. } & \multicolumn{3}{|c|}{ Permeability change in skin sites } & \multirow[b]{2}{*}{ mean \pm SEM } & \multirow[b]{2}{*}{ Saline site } \\
\hline & $\mathbf{a}$ & b & c & & \\
\hline & \multicolumn{3}{|c|}{$c p m$} & & $c p m$ \\
\hline 1 & 1,214 & 1,286 & 1,198 & $1,232 \pm 35$ & 295 \\
\hline 2 & 1,306 & 1,274 & 1,108 & $1,229 \pm 69$ & 271 \\
\hline 3 & 1,222 & 1,248 & 1,194 & $1,221 \pm 18$ & 286 \\
\hline 4 & 1,354 & 1,130 & 1,244 & $1,242 \pm 42$ & 275 \\
\hline 5 & 1,208 & 1,125 & 1,068 & $1,134 \pm 67$ & 225 \\
\hline 6 & 1,188 & 1,396 & 1,360 & $1,315 \pm 54$ & 351 \\
\hline 7 & 1,243 & 1,215 & 1,241 & $1,233 \pm 12$ & 316 \\
\hline
\end{tabular}


TABLE III

Suppression by CFI of Inflammation in Dermal Arthus Sites at $2 h$

\begin{tabular}{|c|c|c|c|c|c|c|c|c|}
\hline \multirow[b]{2}{*}{ Animal no. } & \multicolumn{3}{|c|}{$\begin{array}{c}\text { Intensity of } \\
\text { neutrophil infiltration }\end{array}$} & \multicolumn{3}{|c|}{ Permeability change } & \multicolumn{2}{|c|}{$\begin{array}{l}\text { Reduction in } \\
\text { suppression of } \\
\text { permeability }\end{array}$} \\
\hline & No CFI & CFI & Heated CFI & No CFI & CFI & Heated CFI & CFI & Heated CFI \\
\hline & & & & & cpm & & q & \\
\hline 1 & $2+$ & $\begin{array}{l} \pm \\
\pm *\end{array}$ & & 1,581 & $\begin{array}{l}930 \\
986^{*}\end{array}$ & & $\begin{array}{l}42 \\
38\end{array}$ & \\
\hline 2 & $2+$ & $\begin{array}{l} \pm \\
\pm\end{array}$ & & 1,314 & $\begin{array}{l}726 \\
690\end{array}$ & & $\begin{array}{l}45 \\
48\end{array}$ & \\
\hline 3 & $2+$ & $\begin{array}{l} \pm \\
\pm\end{array}$ & & 1,532 & $\begin{array}{l}682 \\
801\end{array}$ & & $\begin{array}{l}56 \\
48\end{array}$ & \\
\hline 4 & $2+$ & $\begin{array}{l} \pm \\
\pm\end{array}$ & & 1,378 & $\begin{array}{l}649 \\
742\end{array}$ & & $\begin{array}{l}53 \\
46\end{array}$ & \\
\hline 5 & $2+$ & \pm & $2+$ & 1,609 & 997 & 1,482 & 38 & 7 \\
\hline $6 \ddagger$ & $2+$ & \pm & $2+$ & 2,262 & 1,127 & 2,190 & 51 & 4 \\
\hline 7 & $2+$ & \pm & $2+$ & 1,560 & 708 & 1,776 & 55 & 0 \\
\hline 8 & $2+$ & \pm & $2+$ & 1,486 & 947 & & 36 & \\
\hline 9 & $2+$ & \pm & $2+$ & 1,642 & 1,062 & & 35 & \\
\hline
\end{tabular}

* Duplicate sites in each of four animals.

\$ This animal received slightly more radiolabeled permeability marker intravenously than did the other animals.

in the early Arthus reaction (at $2 \mathrm{~h}$ ). Table II indicates that the range of variation between different animals was $328 \mathrm{cpm}$ (animals 5 and 6, values of 1,068 and $1,396)$, which is similar to the maximum variation within a single animal (animal 2, $198 \mathrm{cpm}$ ). These data, taken with the mean values for permeability changes and the standard errors of the mean, as given in Table II, indicate that the changes in permeability in dermal Arthus sites are reasonably reproducible.

The effect of purified CFI ( $12 \mu \mathrm{g}$ per site, representing approximately $10^{-10} \mathrm{~mol}$ ) on development of inflammation in dermal Arthus sites was studied $2 \mathrm{~h}$ after injection of reactants, using nine animals with a total of 25 skin sites (Table III). In all of the positive control sites, the intensity of the neutrophil infiltration was $2+$ (involving walls of vessels and interstitial areas) (Fig. 1). At sites where CFI had been injected, there was minimal evidence of neutrophil infiltration ( \pm , with cells limited to walls of venules) (Fig. 2). The permeability changes (due to leakage of ${ }^{125}$ I-labeled rat IgG) ranged from 1,314 to $2,262 \mathrm{cpm}$ per site, whereas in the presence of CFI, the permeability changes diminished to an extent of $35-56 \%$. If the CFI had been previously heat inactivated, virtually all of the suppression of leukocytic infiltration and permeability changes disappeared (Table III, animals 5-7).
Suppression of hemorrhage in dermal Arthus sites. $4 \mathrm{~h}$ after the injection of antigen and antibody, Arthus vasculitis sites are characterized by the appearance of a central, circular zone of hemorrhage. In 10 different animals, skin sites were prepared by the intradermal injection of antibody alone or antibody with CFI (100 $\mu \mathrm{l}, 12 \mu \mathrm{g})$. In some animals a third site was injected with antibody and heated $\left(56^{\circ} \mathrm{C}\right.$, $2 \mathrm{~h}$ ) CFI. Diameters of hemorrhage were determined. As the data in Table IV indicate, areas of hemorrhage measuring 11-13 $\mathrm{mm}$ were found in all animals at sites injected only with antibody. In companion sites receiving antibody together with CFI, the development of hemorrhage was completely suppressed (Fig. 3 ) in all but one animal in which a small, $4 \mathrm{~mm}$ area of hemorrhage was noted (Table IV, animal 2). In four animals in which dermal sites were injected with heated CFI together with antibody (Table IV, animals 2-4, and 6), the degree of hemorrhage was similar to that found in the positive control (antibody only) sites. These data indicate that purified human CFI can suppress the development of hemorrhage in the inflammatory reaction associated with acute immunologic vasculitis.

Localization of antigen and C3 in vascular lesions. Direct immunofluorescent studies were done on frozen 


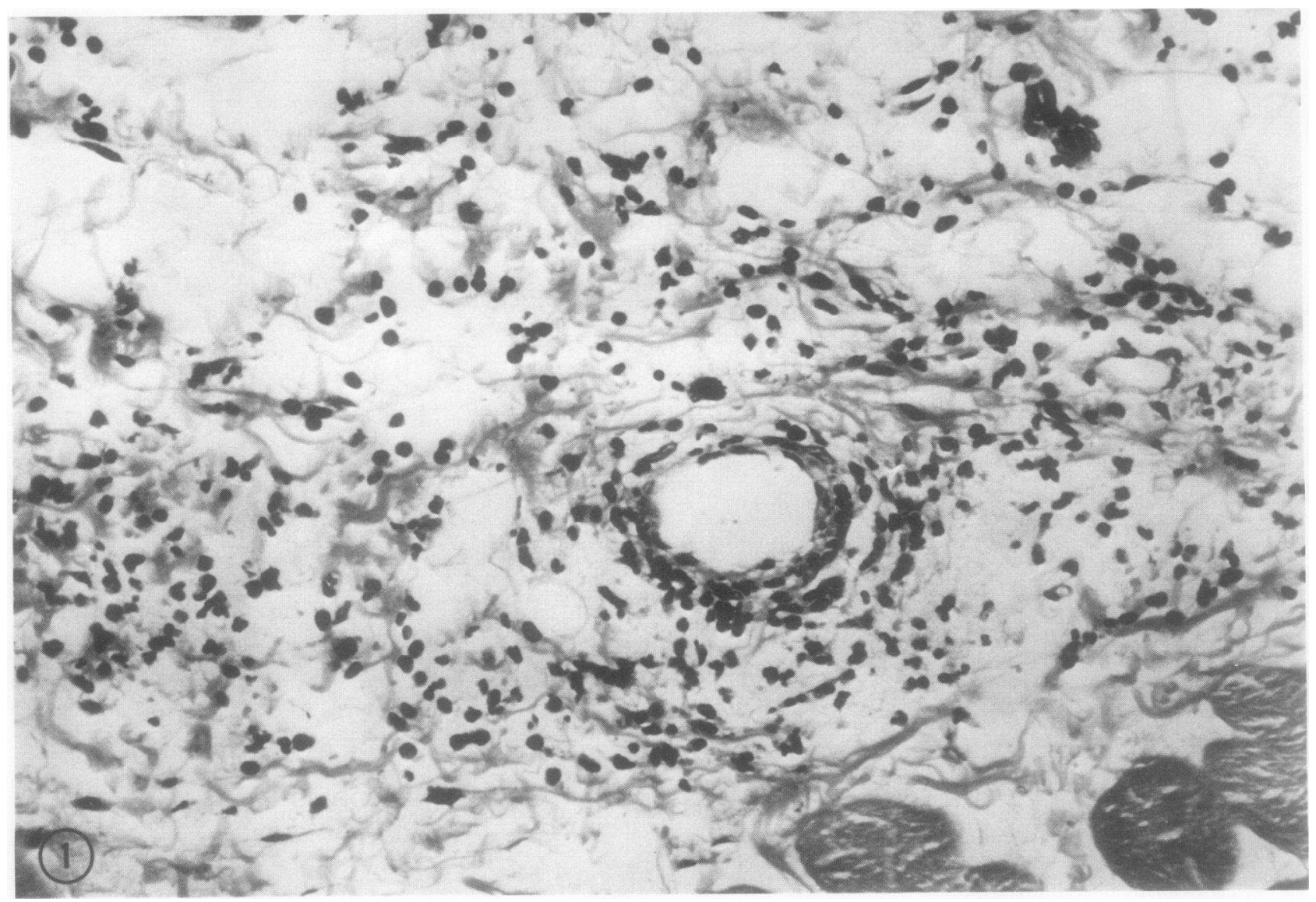

FIGURE 1 Tissue section (formalin fixed and stained with hematoxylin and eosin) of an Arthus reaction obtained at $2 \mathrm{~h}$. This is a positive, control reaction. Neutrophil infiltration has occurred in a perivascular and interstitial location.

sections of all biopsy sites. Tissues from sites injected with antibody alone or antibody together with CFI were stained for antigen (BSA) and C3. In all tissue sections, from both the suppressed as well as the nonsuppressed sites, deposits of BSA and C3 were found in walls of dermal vessels and in the walls of capillaries present between the muscle fibers of the subdermis. No quantitative or qualitative differences were found in the suppressed and in the nonsuppressed sites. These findings indicate that CFI-induced suppression of the inflammatory response in immunologic vasculitis is not due to an interference with the formation and deposition of the immune complexes, or with the subsequent fixation of complement by the complexes.

CFI-induced suppression of immune complexinduced alveolitis. The ability of CFI to suppress the acute inflammatory changes at $2 \mathrm{~h}$ in acute immune complex-induced alveolitis was also assessed. As described above, this model utilizes the same antibody reagents used for the reversed passive dermal Arthus reaction, but in the lung. The intrabronchial adminis- tration of antibody ( $100 \mu \mathrm{g} \mathrm{N}$ anti-BSA) followed by antigen (BSA) intravenously leads to an intense inflammatory reaction in lung with large numbers of neutrophils in alveolar spaces and septae, a marked increase in permeability, and extensive intrapulmonary hemorrhage, as quantitated by extraction of hemoglobin from tissues.

In the positive control groups of eight rats (Table $\mathrm{V}$, animals 1-8) virtually all animals demonstrated a 4+ intensity of neutrophil infiltration, a mean permeability change of $0.84 \pm 0.08$ (milliliters of blood equivalents), and a corrected extractable hemoglobin value of 1.831 \pm 0.393 (determined by an OD at $440 \mathrm{~nm}$ ). In negative, control rats injected intrabronchially with saline instead of antibody, there was minimal infiltration by neutrophils, a mean permeability change of $0.20 \pm 0.01$ and a relatively low value for extractable hemoglobin (Table V, animals 9-11). The mean value of 1.878 \pm 0.145 represents a small amount of hemoglobin and turbidity due to the presence of surfactant. In nine rats in which $150 \mu \mathrm{l}$ CFI $(16 \mu \mathrm{g})$ was mixed with the antibody before intrabronchial injection, seven of 


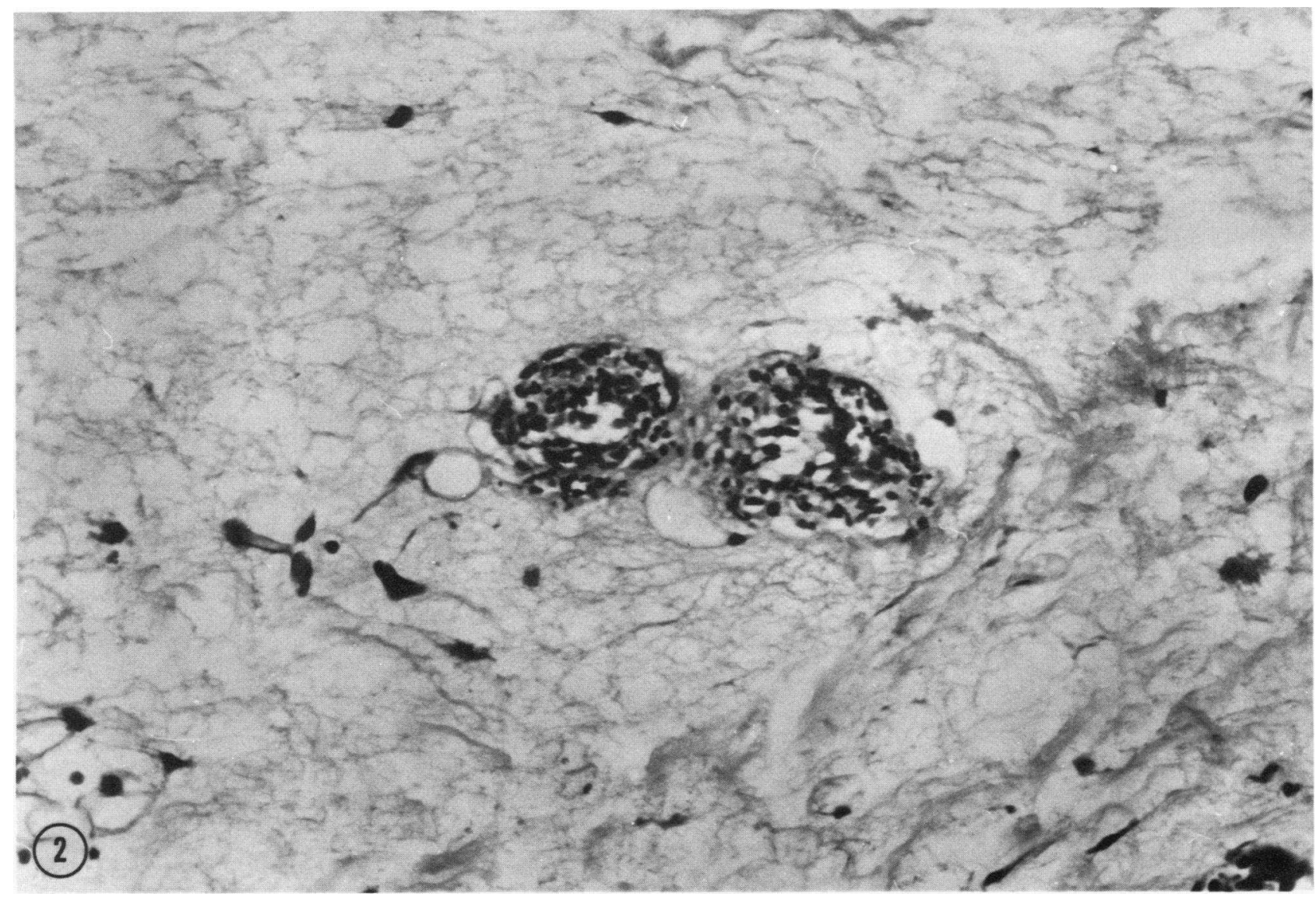

FIGURE 2 Tissue section (processed similar to Fig. 1) of an Arthus reaction that received $12 \mu \mathrm{g}$ purified human CFI. Infiltration by neutrophils is minimal and limited to a perivascular location.

these animals had minimal ( \pm ) infiltrates of neutrophils (Table $\mathrm{V}$, animals 12-20). The change in permeability was virtually completely abolished, with the mean value of $0.26 \pm 0.08$, which was very close to the mean value of the saline controls $(0.20 \pm 0.01)$. The amount of extractable hemoglobin $(0.279 \pm 0.143)$ was also sharply reduced when compared with the value from the positive control animals $(1.831 \pm 0.393)$. In 10 additional animals (Table V, animals 21-30), in which only $5 \mu \mathrm{g}$ CFI was injected with antibody, the observations were limited to assessment of permeability changes. The mean change in permeability was 0.51 \pm 0.06 , a value intermediate between that of the positive controls (animals $1-8,0.84 \pm 0.08$ ) and the group receiving the higher amount of CFI (animals 12-20, $0.26 \pm 0.08$ ). These observations indicate that CFI can induce in a dose-dependent manner suppression of immune complex-induced inflammatory changes.

Frozen sections of lungs from positive controls and from CFI-treated rats were examined by direct immunofluorescence. Antigen (BSA) and antibody (rabbit IgG) were present as granular deposits along alveolar walls. No qualitative or quantitative differences between suppressed and nonsuppressed animals were found. These findings suggest that CFI does not interfere with formation and deposition of immune complexes in vivo.

Lack of interference of CFI with intact complement, immune complex formation, and complement fixation in vitro. The possibility was considered that CFI might interfere with intact complement, the formation of immune complexes, or the fixation of complement in vitro by preformed immune complexes. To investigate the possibilities, $5 \mu \mathrm{g}$ antibody nitrogen (anti-BSA) was mixed with $50 \mu \mathrm{g}$ protein of a purified CFI preparation. $\left(0.5 \mu \mathrm{l}^{3}\right.$ of this CFI would totally inactivate the leukotactic activity generated in $1.0 \mathrm{ml}$ rat or human serum which had previously been activated with zymosan.) Thereafter, $1 \mu \mathrm{g}$ N BSA (the amount of antigen equivalence) was added and the mixture incubated at $37^{\circ} \mathrm{C}$ for $1 / 2 \mathrm{~h}$. (These are the same reagents used for the in vivo experiments.) $0.5 \mathrm{ml}$

\footnotetext{
${ }^{3}$ Containing $1.0 \mu \mathrm{g}$ protein.
} 
TABLE IV

CFI-Induced Suppression of Hemorrhage in Arthus Vasculitis*

\begin{tabular}{cccc}
\hline & \multicolumn{3}{c}{ Treatment of Arthus site } \\
\cline { 2 - 4 } Animal no. & None & CFI $(12 \mu \mathrm{g})$ & $\begin{array}{c}\text { Heated CFI } \\
\left(56^{\circ} \mathrm{C}, 2 \mathrm{~h}\right)\end{array}$ \\
\hline & \multicolumn{3}{c}{ diameter of hemorrhage, $m$ m } \\
1 & 11 & 0 & ND $\$$ \\
2 & 12 & 4 & 10 \\
3 & 11 & 0 & 11 \\
4 & 13 & 0 & 10 \\
5 & 13 & 0 & ND \\
6 & 11 & 0 & 12 \\
7 & 12 & 0 & ND \\
8 & 13 & 0 & ND \\
9 & 11 & 0 & ND \\
10 & 12 & 0 & ND \\
\hline
\end{tabular}

* Sites examined at $4 \mathrm{~h}$.

$\$$ Antibody $(100 \mu \mathrm{l})$ was diluted with $100 \mu \mathrm{l}$ saline or $100 \mu \mathrm{l}$ CFI preparation.

$\S$ Not done.

fresh rat serum was then added and incubated for an additional $1 / 2 \mathrm{~h}$ at $37^{\circ} \mathrm{C}$. $\mathrm{CH}_{50}$ assays were performed, according to details given elsewhere (2). The immune complexes formed in the presence or absence of CFI totally inactivated the serum complement ( $<2 \mathrm{CH}_{50}$ of $20 \mathrm{U}$ remained in the serum). In the serum to which only antibody was added the presence or absence of CFI made little difference; the $\mathrm{CH}_{50}$ values were 20 and $19.5 \mathrm{U}$, respectively. From these data it can be concluded that CFI does

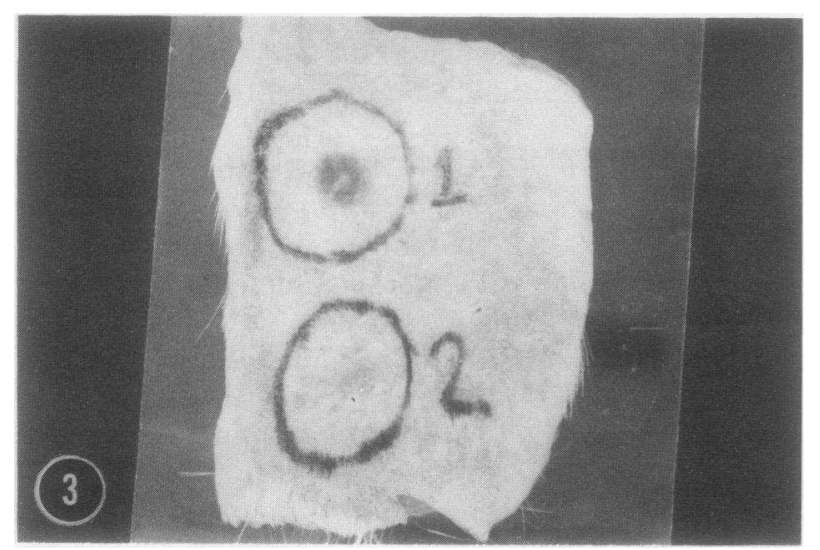

Figure 3 Two reversed, passive Arthus sites, one of which (no. 2) was injected with antibody together with CFI. A 12-mm zone of hemorrhage was seen in the control, positive site (no. 1) whereas the CFI injected site was free of hemorrhage. The dark outer rings were drawn with pen to indicate the areas biopsied for radioactivity measurement (described in Table II). (Magnified $1.5 \times$ in original picture.) not demonstrably alter intact complement, nor does it interfere with formation in vitro of complement-fixing immune complexes.

An additional experiment was carried out to determine whether CFI has an effect on intact human C5. For this experiment, a hemolytic measurement of $1 \mu \mathrm{g}$ purified human C5 was performed (14). In a 50- $\mu$ l volume, C5 was incubated with $20 \mu \mathrm{l}$ Veronal buffer or with $20 \mu \mathrm{l}(40 \mu \mathrm{g}) \mathrm{CFI}$ for $1 / 2 \mathrm{~h}$ at $37^{\circ} \mathrm{C}$. Then, to these mixtures was added $0.2 \mathrm{ml} \mathrm{EAC14}$ $\left(10^{6}\right.$ cells kindly provided by Dr. Robert McLean, University of Connecticut Health Center, Farmington, Conn.), $0.1 \mathrm{ml}$ human serum pretreated with $1 \mathrm{M} \mathrm{KSCN}$, and $100 \mu \mathrm{g}$ purified $\mathrm{C} 3$. Before centrifugation to obtain supernatant fluids, $2.0 \mathrm{ml}$ Veronal buffer was added. The duplicate values of optical densities at 450 $\mathrm{nm}$ for the CFI-treated C5 were 0.091 and 0.111; the buffer-treated C5, 0.101 and 0.095; and for C5 that was completely untreated, 0.095 and 0.098 . These results suggest that intact $\mathrm{C} 5$ is resistant to hemolytic inactivation by CFI.

\section{DISCUSSION}

The studies described above indicate that human CFI is a potent inhibitor of inflammatory reactions triggered by immune complexes deposited in tissues. It has been previously shown that these reactions require complement and that, in the case of the reversed passive Arthus reaction, this is largely due to C5-derived leukotactic mediators generated locally by immune complex-induced activation of the complement system $(13,15,16)$. An additional factor apparently involved in the pathogenesis of the reaction may be the C5-cleaving enzyme derived from lysosomal granules of neutrophils $(15,16)$. A similar set of requirements for the immune complex-induced alveolites models has been demonstrated (11). There is abundant evidence that the intensity of the Arthus reaction, defined both by the permeability changes as well as hemorrhage, is quantitatively related to the numbers of infiltrating neutrophils $(2,3,11)$. There is strong support for the conclusion that the manifestations of tissue damage are attributable to enzymes delivered from neutrophils (16). Thus, any agent which depresses, whether by a direct or an indirect effect, the accumulation of neutrophils can be expected to reduce the degree of hemorrhage and changes in permeability. In earlier studies suppression was accomplished by neutrophil depletion (with specific antibody or with nitrogen mustard (3), with corticosteroids or chloroquine (1), and with complement-inactivating agents (including cobra factor, heat-aggregated IgG, anti-C3, zymosan, and carrageenan) $(2,3,11)$. The problems secondary to the use of these agents are well known. In addition, consumptive depletion or specific 
TABLE V

Suppression by CFI of Acute Immune Complex-Induced Alveolitis*

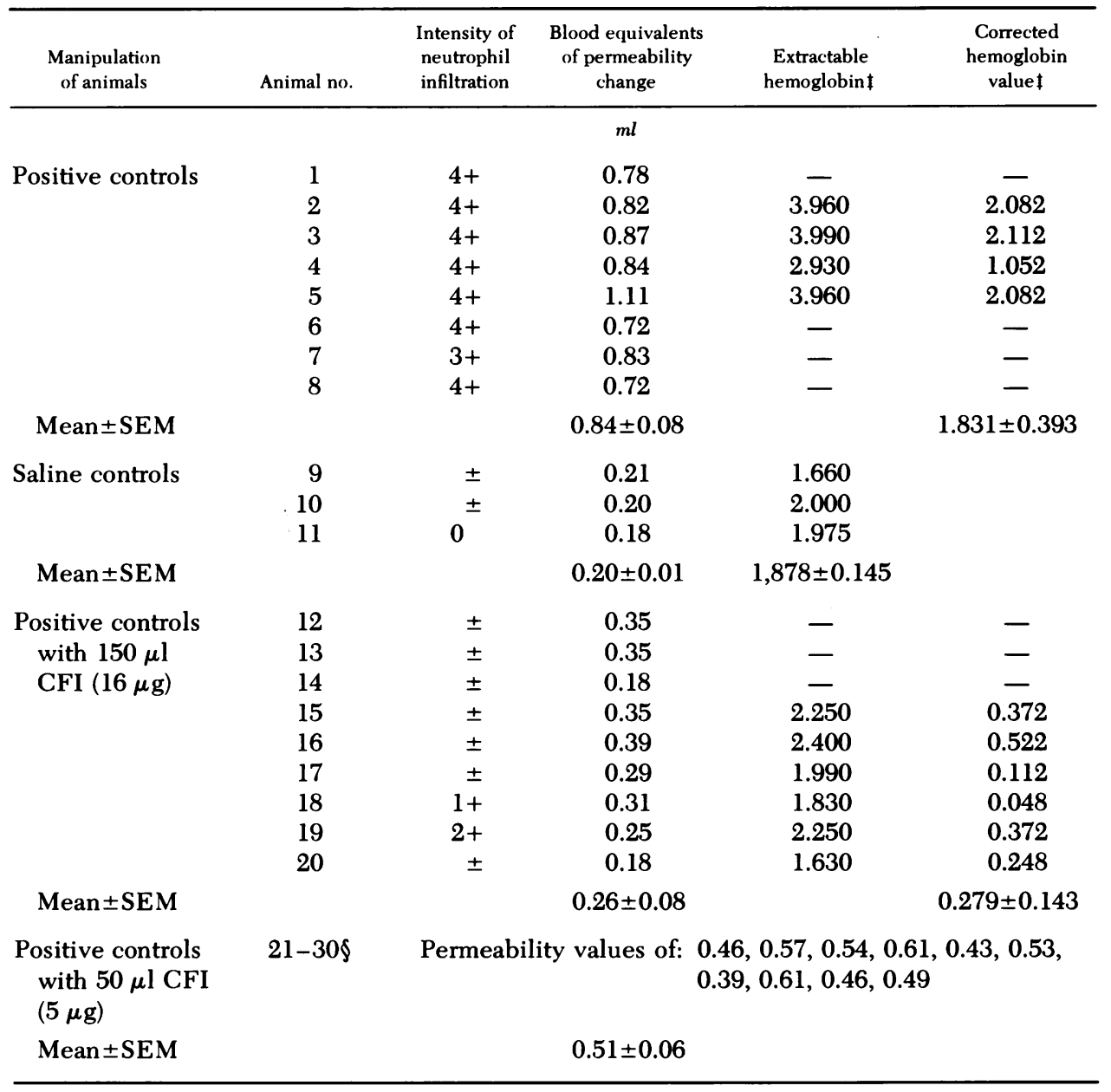

* Details of all measurements are described in reference 11.

$\ddagger$ Determined by an OD at $\mathbf{4 4 0} \mathrm{nm}$.

$\$$ In animals 21-30, observations were limited to permeability changes.

inactivation of the complement system is fraught with the potential problems of compromised host resistance. CFI is an ideal candidate since it has a specific inhibitory effect on the complement-derived mediators responsible for the Arthus reaction $(5,12,13)$. It should be pointed out that as little as $12 \mu \mathrm{g}$ CFI, which represents $<10^{-10} \mathrm{~mol}$, is able to suppress completely the hemorrhage and as much as one-half of the permeability change in the dermal Arthus reaction. In the case of the lung, CFI almost completely suppresses infiltration by neutrophils, permeability changes, and hemorrhage. These are impressive findings, since, to suppress the reactions by neutrophil depletion, it is necessary to reduce the neutrophil count in blood to less than 500 cells $/ \mathrm{mm}^{3}$ blood $(2,3,11)$. Complement reduction so as to block development of the reactions requires complete inactivation of the total hemolytic activity of serum and reduction of C3 to $<5 \%$ of its normal level $(11,13,15)$. Corticosteroid treatment of guinea pigs sufficient to inhibit development of the Arthus reaction requires $>50 \mathrm{mg}$ for each animal (1).

Our studies do not provide any evidence that CFI interferes with the development of immunologically induced inflammatory reactions by an effect on intact complement components. Neither is there any evidence that the formation in vitro of complementfixing immune complexes is interferred with by the presence of CFI. There is a possibility that CFI, aside from its ability to destroy complement-derived leukotactic factors, might be able to alter permeability factors. If it unexpectedly has an ability to impair the effects of vasoactive amines, this is probably a moot point, since all studies to date have provided 
negative evidence for the role of vasoactive amines in the Arthus reaction (reviewed in reference 17). Although it has been demonstrated that bradykinin can be inactivated by CFI (6), no statements can be made regarding the role of this kinin in immune complex-induced inflammatory reactions, since no direct and highly specific method for blocking the generation of, or the action of, bradykinin in vivo has yet been devised.

The demonstration that CFI can block immune complex-induced and complement-mediated inflammatory reactions in rats provides added support for the role of CFI as an important regulator of the inflammatory system. It has been recently demonstrated that elevated CFI levels occur in Hodgkin's disease (6), hepatic cirrhosis (8), sarcoidosis (9), and in lepromatous leprosy (7). In the last instance, a good correlation exists between elevated levels of the inhibitor and the inability of the patients to express cellular inflammatory reactions in the skin. Similar correlations between defective inflammatory responses in humans and the presence of a serum associated chemotactic inhibitor with CFI-like properties have been reported by others (18).

To what extent CFI will be useful in blocking other inflammatory reactions is as yet not known. On the other hand, the results reported in this paper give considerable promise that CFI, a naturally occurring inhibitor of the leukotactic system, may represent a new and highly specific approach to anti-inflammatory therapy.

\section{ACKNOWLEDGMENT}

This paper was supported by National Institutes of Health, grants AI 09651 and AI 13910.

\section{REFERENCES}

1. Ward, P. A. 1966. The chemosuppression of chemotaxis. J. Exp. Med. 124: 209-226 (and plates 15, 16).

2. Ward, P. A., and C. G. Cochrane. 1965. Bound complement and immunologic injury of blood vessels. J. Exp. Med. 121: 215-234 (and plates 15, 16).

3. Cochrane, C. G., W. O. Weigle, and F. J. Dixon. 1959.
The role of polymorphonuclear leukocytes in the initiation and cessation of Arthus vasculitis. J. Exp. Med. 110: 481-494 (and plates 22-25).

4. Vane, J. R. 1972. Prostaglandins in the inflammatory response. In Inflammation Mechanisms and Control. I. H. Lepow and P. A. Ward, editors. Academic Press, Inc., New York. 261-279.

5. Berenberg, J. L., and P. A. Ward. 1973. The chemotactic factor inactivator in normal human serum. $J$. Clin. Invest. 52: 1200-1206.

6. Ward, P. A., and J. Ozols. 1976. Characterization of the protease activity of the chemotactic factor inactivator. J. Clin. Invest. 58: 123-129.

7. Ward, P. A., and J. L. Berenberg. 1974. Defective regulation of inflammatory mediators in Hodgkin's disease. Supernormal levels of chemotactic-factor inactivator. N. Engl. J. Med. 290: 76-80.

8. Ward, P. A., S. Goralnick, and W. E. Bullock. 1976. Defective leukotaxis in patients with lepromatous leprosy. J. Lab. Clin. Med. 87: 1025-1032.

9. Maderazo, E. G., P. A. Ward, and R. Quintiliani. 1975. Defective regulation of chemotaxis in cirrhosis. J. Lab. Clin. Med. 85: 621-630.

10. Maderazo, E. G., P. A. Ward, C. L. Woronick, J. Kubik, and A. C. DeGraff, Jr. 1976. Leukotactic dysfunction in sarcoidosis. Ann. Intern. Med. 84: 414-419.

11. Johnson, K. J., and P. A. Ward. 1974. Acute immunologic pulmonary alveolitis. J. Clin. Invest. 54: 349-357.

12. Till, G., and P. A. Ward. 1975. Two distinct chemotactic factor inactivators in human serum. J. Immunol. 114: 843-847.

13. Ward, P. A., and J. H. Hill. 1972. Biologic role of complement products. Complement-derived leukotactic activity extractable from lesions of immunologic vasculitis. J. Immunol. 108: 1137-1145.

14. Chapman, W. E., and P. A. Ward. 1976. Changes in C3 metabolism during protozoan infection (Babesia rodhaini) on rats. J. Immunol. 116: 1284-1288.

15. Ward, P. A., and J. H. Hill. 1970. C5 chemotactic fragments produced by an enzyme in lysosomal granules of neutrophils. J. Immunol. 104: 535-543.

16. Cochrane, C. G. 1968. Immunologic tissue injury mediated by neutrophilic leukocytes. Adv. Immunol. 9: 97-162.

17. Cochrane, C. G., and A. Janoff. 1974. The Arthus reaction. A model of neutrophil and complement-mediated injury. In The Inflammatory Process, Volume III. B. W. Zweifach, L. Grant, and R. T. McCluskey, editors. Academic Press Inc., New York. 2nd edition. 85- 162.

18. Van Epps, D. E., D. L. Palmer, and R. C. Williams, Jr. 1974. Characterization of serum inhibitors of neutrophil chemotaxis associated with energy. J. Immunol. 113: 189-200. 